\title{
SUCESSO NO CAMPO ESCOLAR: CONDICIONANTES PARA ENTRADA NA UNIVERSIDADE NO BRASIL*
}

\author{
Fernando Gonçalves de Gonçalves ${ }^{1}$ (D) \\ Marília Patta Ramos ${ }^{1}$ (D
}

\begin{abstract}
RESUMO: Acessar o ensino superior no Brasil pode ser visto como um relativo sucesso escolar, pois apenas $14 \%$ dos jovens o frequentavam em 2009. O objetivo desse artigo foi mapear as condiçóes necessárias a esse sucesso. A metodologia foi quantitativa, baseada nos dados socioeconômicos do Exame Nacional do Ensino Médio (ENEM) 2009/Sistema de Seleção Unificada (SISU) 2010, de forma a buscar os condicionantes do acesso ao ensino superior. O referencial teórico baseou-se no estruturalismo genético e seus desdobramentos na Nova Sociologia da Educação. Os resultados indicam que, apesar de o capital cultural ser importante, como mostra a influência dos indicadores que o operacionalizam (escolaridade dos pais, hábitos de leitura etc.), o capital econômico é determinante sobre as chances de sucesso. Cursos que exigem nota maior para o ingresso filtram candidatos advindos das classes superiores.
\end{abstract}

Palavras-chave: Sucesso escolar. Reprodução escolar. Exame Nacional do Ensino Médio. Ensino superior.

\section{SUCCESS IN THE EDUCATIONAL FIELD: CONDITIONS FOR ENTRY INTO THE UNIVERSITY IN BRAZIL}

ABSTRACT: The Access to higher education in Brazil can be considered as a relative success in school, since only $14 \%$ of young people attended it in 2009. The objective of this article is to map the conditions necessary for this success. The methodology is quantitative, based on the socioeconomic data of the ENEM 2009 / SISU 2010, in order to look for the conditions of access to higher education. The theoretical framework was based on genetic structuralism and its developments in the New Sociology of Education. The results indicate that, although cultural capital is important, as shown by the influence of the indicators that operate it (parental schooling, reading habits, etc.), economic capital is especially determinant on the chances of success. Courses requiring a higher grade for admission filter candidates from the upper classes.

Keywords: Educational success. School reproduction. Exame Nacional do Ensino Médio. Higher education.

\footnotetext{
*Este projeto é o resultado parcial e adaptado da pesquisa de mestrado Sucesso no Campo Escolar de Estudantes Oriundos de Classes Populares: Estrutura e Trajetórias, financiada pela Coordenação de Aperfeiçoamento de Pessoal de Nível Superior (CAPES).

${ }^{1}$ Universidade Federal do Rio Grande do Sul - Porto Alegre (RS), Brasil. E-mails: goncalves.goncalves@ufrgs.br; mariliaramos68@gmail.com

DOI: 10.1590/ES0101-73302019188393
} 


\title{
ÉXITO EN EL CAMPO ESCOLAR: CONDICIONANTES PARA ENTRADA EN LA UNIVERSIDAD EN BRASIL
}

\begin{abstract}
RESUMEN: Acceder a la enseńanza superior en Brasil puede ser visto como un relativo éxito escolar, pues apenas el 14\% de los jóvenes la frecuentaban en 2009. El objetivo de ese artículo fue mapear las condiciones necesarias a ese éxito. La metodología fue cuantitativa, basada en los datos socioeconómicos del Examen Nacional de la Enseñanza Media (ENEM) 2009/Sistema de Selección Unificada (SISU) 2010, de forma de buscar los condicionantes del acceso a la enseñanza superior. El referencial teórico se basó en el estructuralismo genético y sus desdoblamientos en la Nueva Sociología de la Educación. Los resultados indican que, a pesar de que el capital cultural sea importante, como muestra la influencia de los indicadores que lo operacionalizan (escolaridad de los padres, hábitos de lectura etc.), el capital económico es determinante sobre las chances de éxito. Cursos que exigen nota mayor para el ingreso filtran candidatos advenidos de las clases superiores.
\end{abstract}

Palabras clave: Éxito escolar. Reproducción escolar. Examen Nacional de la Enseñanza Media. Enseñanza superior.

\section{Introdução e objetivo}

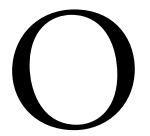

acesso à educação superior é, no Brasil, o ponto fulcral de consolidação das desigualdades educacionais. Segundo a Pesquisa Nacional por Amostra de Domicílios (PNAD) (BRASIL, 1992-2005), a taxa líqui$\mathrm{da}^{1}$ de acesso ao ensino superior passou de 4\% em 1992 para 18\% em 2015. A taxa bruta, por sua vez, atingiu 50\%, mas é considerada baixa quando comparada com a de países desenvolvidos ou mesmo da América Latina (GUADILLA, 2007). Em 2015, a Argentina atingiu taxa bruta de 85\%, o Chile de 88\%, a Espanha de $89 \%$, a Coreia do Sul de $93 \%$ (embora tenha atingido $101 \%$ em 2011) e a média para os países desenvolvidos é de 75\% (UNESCO, 2018). Adicionalmente a isso, fortes condicionantes socioeconômicos se correlacionam ao acesso, apesar das políticas de ampliação implantadas nas últimas décadas ${ }^{2}$. Ainda em 2015, segundo a PNAD, 40\% dos estudantes do ensino superior provinham do quintil de renda mais rico da população (BRASIL, 1992-2005). Da mesma forma, os negros eram $54 \%$ da população brasileira de acordo com o último censo (IBGE, 2010), mas apenas $43 \%$ dos estudantes do sistema de ensino superior.

Assim, podemos afirmar que quem chega ao ensino superior brasileiro se aproximou de uma situação de relativo sucesso escolar ${ }^{3}$, pois sobreviveu aos pontos de bifurcação, nos quais poderia abandonar o sistema escolar, e atingiu o 
ápice do sistema. Mesmo se levarmos em conta que há outros momentos da vida escolar nos quais os estudantes são fortemente selecionados - ainda de acordo com a PNAD (BRASIL, 1992-2005), 62\% dos jovens entre 15 e 17 anos estavam cursando o ensino médio em 2015 - é na passagem da educaçáo básica para a superior que os mecanismos de reproduçáo social parecem atuar mais fortemente. Da mesma forma, o diploma universitário reforça, posteriormente, as desigualdades sociais: na média dos países da Organização para a Cooperação e Desenvolvimento Econômico (OECD), pessoas com educação superior ganhavam, em 2015, $56 \%$ a mais do que pessoas com ensino médio completo. No Brasil, a diferença chegava a 149\% (OECD, 2017). Tendo isso em vista, o objetivo desse artigo foi mapear as influências dos capitais econômico e cultural, bem como de variáveis demográficas gerais, sobre as chances de acesso ao ensino superior. Dessa forma, visa-se entender quais são as condiçóes sociais necessárias ao sucesso escolar desses estudantes, definido como a possibilidade de acesso ao ensino superior através do sucesso no Exame Nacional do Ensino Médio.

\section{Método}

Optamos por trabalhar com o banco de dados gerado a partir do questionário socioeconômico do ENEM de 2009 com o objetivo de verificar como indicadores de capital cultural e capital econômico, bem como variáveis demográficas, influenciam nas chances de um estudante atingir uma situação de sucesso escolar, ou seja, de acesso ao ensino superior. A escolha do banco de 2009 ocorreu por dois motivos: primeiramente, 2009 foi o ano de reformulação do ENEM, quando passou a ser utilizado para substituir os vestibulares em universidades federais, por meio do Sistema de Seleção Unificada; em segundo lugar, os questionários socioeconômicos, a partir dessa data, foram simplificados, passando a fornecer menos informaçóes.

Para quantificarmos uma possível definição de sucesso, buscamos as notas de corte mínimas para a seleção em alguns cursos ofertados pelo SISU de 2010. Para este trabalho, selecionamos três cursos e buscamos, entre todas as universidades federais, as notas mínimas de corte para aprovação daquele ano: Pedagogia (586), Administração (699) e Medicina (782) ${ }^{4}$. Acima dessas notas, em cada um dos modelos, obtém-se uma situaçáo de sucesso escolar, e abaixo, uma situação de insucesso. Com a variável dependente dicotomizada, podemos aplicar a técnica da regressão logística ${ }^{5}$ aos nossos dados, buscando, como preditores, diversos indicadores relacionados às condiçóes sociais e aos capitais incorporados pelo estudante.

O caminho dos conceitos teóricos aos indicadores empíricos está explicitado no Quadro 1. Cabe lembrar que, por se tratar de um questionário autoaplicado, há muito risco de respostas equivocadas (por exemplo, por não 
compreensão da pergunta). Da mesma forama, as categorias utilizadas para compor as variáveis podem não ser as mais adequadas para operacionalizarem os conceitos com os quais estamos trabalhando. Há, também, um grande viés de seleção entre os estudantes que se disponibilizaram a realizar o ENEM, o que é exacerbado pelo fato de que levamos em consideração, em nossa análise, apenas os estudantes que participaram de ambos os dias das provas e não zeraram nenhuma delas, ou seja, a demanda qualificada ${ }^{6}$. Da mesma forma, há muitos missings nas respostas, o que exacerba o viés de seleção (é de se esperar que os estudantes que preenchem corretamente o questionário sejam, de alguma forma, diferentes daqueles que não o fazem), o que limita os achados nesse tipo de estudo. Ainda assim, levando o que foi exposto em conta, algumas conclusóes significativas do ponto de vista sociológico podem ser extraídas de um material empírico táo rico e representativo quanto o do questionário socioeconômico do ENEM.

\section{Quadro 1}

Modelo de análise.

\begin{tabular}{|c|c|c|c|}
\hline Variáveis & Conceitos & Dimensóes & Indicadores \\
\hline \multirow{4}{*}{ Independentes } & $\begin{array}{c}\text { Capital } \\
\text { econômico }\end{array}$ & -.-.-.-- & $\begin{array}{l}\text { Renda familiar em salários mínimos, } \\
\text { densidade do domicílio, se trabalhou } \\
\text { durante o ensino médio. }\end{array}$ \\
\hline & \multirow{3}{*}{$\begin{array}{l}\text { Capital } \\
\text { cultural }\end{array}$} & $\begin{array}{l}\text { Incorporado } \\
\text { (herdado) }\end{array}$ & Pai e mãe possuem ensino superior \\
\hline & & $\begin{array}{l}\text { Incorporado } \\
\text { (adquirido) }\end{array}$ & Tipos e frequência de leitura (fatores 1 e 2$)^{*}$ \\
\hline & & Iinstitucionalizado & $\begin{array}{l}\text { Estudou em escola particular / reprovou no } \\
\text { ensino médio / estudou no turno noturno }\end{array}$ \\
\hline \multicolumn{3}{|c|}{ Variáveis demográficas: } & $\begin{array}{c}\text { Idade / sexo / cor ou raça / região do país / } \\
\text { religião / tem filhos }\end{array}$ \\
\hline \multirow{3}{*}{ Dependentes } & \multirow{3}{*}{$\begin{array}{l}\text { sucesso } \\
\text { escolar }\end{array}$} & $\begin{array}{l}\text { Extremamente } \\
\text { competitivo }\end{array}$ & $\begin{array}{l}\text { Nota de corte para o curso de Medicina } \\
\text { (1\% dos estudantes): } 782\end{array}$ \\
\hline & & $\begin{array}{l}\text { Altamente } \\
\text { competitivo }\end{array}$ & $\begin{array}{c}\text { Nota de corte para o curso de } \\
\text { Administração (7\% dos estudantes): } 699\end{array}$ \\
\hline & & $\begin{array}{l}\text { Relativamente } \\
\text { competitivo }\end{array}$ & $\begin{array}{l}\text { Nota de corte para o curso de Pedagogia } \\
\text { (36\% dos estudantes): } 586\end{array}$ \\
\hline
\end{tabular}

* Por meio da técnica de análise fatorial, extraímos dois fatores a partir dos hábitos de leitura dos estudantes. O fator 1 é composto da frequência (nunca, às vezes ou frequentemente) de leitura de revistas humor, de quadrinhos, para adolescentes, sobre celebridades, automóveis, saúde ou religião. Já o fator 2 é composto da frequência de hábitos de leitura de jornais, revistas de informação geral, revistas de divulgação cientifica, revistas sobre educação, livros de ficção e de não ficção, enciclopédias, manuais etc. De forma interessante, o primeiro fator agrupou as leituras consideradas culturalmente menos legitimas, enquanto o segundo fator agrupou aquelas consideradas mais legitimas. Como era esperado, o primeiro fator se correlaciona negativamente com a nota final do exame (Pearson: -0,257), enquanto o segundo fator se correlaciona positivamente (Pearson: 0,196). Ou seja, hábitos frequentes de leituras consideradas culturalmente menos legítimas estão correlacionados com um desempenho pior do que simplesmente não ler nada. 


\section{Capital cultural e reprodução}

Pierre Bourdieu $(1989 ; 2007)$ define capital não apenas em referência à sua dimensão econômica mas, também, constrói teoricamente dois outros modelos de capital - o social e o cultural (além do simbólico, que permeia todos). O conceito de capital, advindo primeiramente da economia, foi utilizado pelo autor para estudar e explicar as desigualdades escolares, como uma figura para falar de ganhos e vantagens que alguns agentes sociais e suas famílias possuem e que são mobilizados, conscientemente ou não, para conduzi-los a um nível mais elevado no espaço social. O autor constrói esses conceitos frente a evidências empíricas que demonstravam que as desigualdades no sistema educacional não eram facilmente explicáveis apenas em termos de relação entre resultados educacionais e nível de renda.

Bourdieu (1989; 2007) entende o espaço social como constituído de diferentes campos de conflitos onde os agentes desenvolvem estratégias que resultem em manter ou melhorar sua posição nesse mesmo espaço. O capital cultural está, nesse sentido, relacionado com a configuraçáo familiar do indivíduo. Segundo o autor, o capital cultural existe sob três dimensóes: incorporado, institucionalizado e objetivado. O capital cultural incorporado é aquele que o agente traz herdado de sua família ou adquirido em sua experiência. O capital cultural objetivado ${ }^{7}$ ocorre na forma de bens de cultura, como livros, pinturas, obras de arte etc. Por último, o capital cultural institucionalizado ocorre sob a forma de diplomas escolares - é aquele sancionado pelo Estado. Por sua vez, o capital social é o conjunto de relações sociais que o agente mantém, que também podem ser mobilizadas e convertidas em outros tipos de capital. A partir do volume de capitais acumulados e sua composição, os indivíduos são classificados na estrutura social em classes altas, médias ou populares e possuem um habitus (formas de pensar, ser e agir) de classe específico.

Tendo como foco o sistema educacional, Bourdieu e Passeron (1982; 2008) estudaram as relaçóes desses capitais com o sistema escolar. Os autores demonstraram que, ao contrário do que muitos economistas afirmaram, as desigualdades escolares não poderiam ser reduzidas a meras diferenças de condição econômica. O sistema educacional, sob aparência democrática e igualitária, operaria como um potente mecanismo reprodutor das desigualdades sociais. Como o sistema educacional valoriza os signos culturais dominantes, que são os mesmos das classes que possuem uma relação privilegiada com a cultura dominante, a saber, grandes fraçóes das classes médias e altas, os estudantes provenientes das classes populares enfrentam, desde cedo, a violência simbólica do sistema escolar. Enquanto os estudantes provenientes das classes com grande quantum de capital cultural transitam com facilidade pelo sistema escolar, sendo recompensados desde cedo por isso, os estudantes das classes populares se veem diante de um mundo 
novo, no qual não foram inseridos desde a sua socialização primária, fundamento na personalidade dos agentes, como aqueles outros - das classes dominantes que, desde cedo, mantiveram contato com a palavra escrita, com a literatura, com as artes e outros signos culturais valorizados na sociedade ocidental moderna e no sistema escolar. Assim, as diferenças prévias de socialização são tratadas pelo sistema escolar como diferenças de mérito individual.

Enquanto o que caracteriza as classes altas é a posse, em quantidade significativa, de capital econômico (embora normalmente também exista algum capital cultural), o que caracterizaria as classes populares é a ausência ou quase ausência dos capitais impessoais. As classes médias (ou pelo menos grande parte de suas fraçóes) se caracterizariam pelo domínio do capital cultural em suas diferentes formas (principalmente na sua forma institucionalizada, a partir dos títulos sancionados pelo Estado), embora alguma quantidade de capital econômico sempre (ou quase sempre) esteja presente. Assim, o capital cultural — tornado legítimo simbolicamente em grande parte pelo sistema escolar — é a forma de capital que garante a posiçấo social relativamente dominante da classe média, em uma sociedade moderna.

Cabe lembrar também que, ao mesmo tempo em que o ensino, em seus diferentes níveis e de forma gradual, se democratiza, ocorre um fenômeno identificado como inflação de diplomas (BOURDIEU, 2007). Os títulos, que anteriormente garantiam uma posiçáo mais elevada ao agente que os detinham, depois que mais pessoas passam a possuí-los, já não valem a mesma coisa. Sendo assim, enquanto antes do boom do ensino superior em alguns países europeus nos anos 1950 e 60, um título de ensino médio já garantia uma posição relativamente confortável na alocação de cargos e posições, sejam públicas ou privadas, após a expansão do ensino superior (que na maioria dos países desenvolvidos atinge, hoje, de 25 a 50\% da população adulta) (OECD, 2017) passa a garantir apenas o acesso a posições subalternas. Os próprios títulos de ensino superior, nesse novo momento, precisam ser complementados por estudos pós-graduados para garantirem as mesmas posições que facilmente garantiam antes.

Os dados quantitativos construídos pelos autores comprovaram essa tendência à reproduçáa. A sociologia trabalha, porém, com regularidades tendenciais, não com leis semelhantes às das hard sciences. Assim, toda tendência estatisticamente significativa possui seus outliers, ou casos fora da curva, já que os modelos não conseguem condensar em variáveis fechadas toda a complexidade do universo social. Assim, sempre resta um erro (advindo seja da precariedade dos instrumentos de mediçấo, seja da própria complexidade e multicausalidade da sociedade), algo que as variáveis escolhidas não conseguiram captar.

Lahire (1997), em Sucesso escolar nos meios populares: as razóes do improvável, realizou entrevistas em profundidade com mais de duas dezenas de crianças - e suas famílias — oriundas de meios familiares pertencentes às classes populares e encontrou 
vários casos de sucesso escolar em crianças que, teoricamente, estariam predestinadas ao fracasso escolar. Esse sucesso improvável não é, porém, aleatório. Como explica o autor, há regularidades tendenciais causando a reprodução social por meio da escola. Da mesma forma, há também regularidades por trás desses casos de sucesso.

As famílias populares, mesmo incorporando parcamente os capitais impessoais, já têm consciência do papel do sistema escolar na distribuição das posiçóes sociais. Sendo assim, muitas delas adotam estratégias de ascensão social por meio do sistema escolar. Dessa forma, em diferentes graus, elas investem fortemente tempo e recursos no sistema escolar, e, por conta de uma série de características familiares, esse investimento pode dar resultado ou não. Por outro lado, a simples existência de capital cultural em quantidade significativa não garante que ele será transmitido. Isso ocorre, por exemplo, se o pai que detém esse capital cultural náo participa ativamente da educação do filho ou, então, há um grande investimento em capital cultural objetivado (livros, enciclopédias, dicionários, computadores etc.) mas as crianças são deixadas sozinhas na apreensão desses signos culturais, sem que o adulto que possui capital cultural incorporado pratique a mediação necessária.

Derouet (2002), por sua vez, nos fala dos desafios postos à sociologia da educação francesa com a segunda explosão escolar na segunda metade do século XX. A primeira explosão escolar aconteceu ainda no século XIX com a criação de um modelo duplo: a escola primária, compulsória, universal e gratuita para os filhos das classes populares e o modelo de liceus para as classes médias e superiores, que permitiam o acesso ao extremamente restrito ensino superior da época. Com a segunda explosão escolar, o acesso à educação secundária praticamente se universalizou e a educação superior multiplicou várias vezes sua taxa de acesso, o que permitiu que vários estudantes com origem nas classes populares acessassem esse nível de ensino e que acabou levando, de forma paradoxal, à desvalorização dos diplomas, tema bastante discutido por Bourdieu (2007). Embora os cargos e funções aos quais determinados diplomas de nível médio ou superior garantiam o acesso antes da segunda explosão tenham aumentado de número com o crescimento econômico do pós-guerra francês, esse crescimento não acompanhou o aumento exponencial do número de formados. Logo, outros capitais, como o capital social, passaram a exercer muito mais influência no acesso aos cargos e posiçóes aos quais antes apenas o capital cultural institucionalizado, na forma de diplomas, permitia fácil acesso.

No Brasil, é provável que estejamos passando por uma situação análoga à da segunda explosão escolar nas últimas duas décadas. Embora ainda estejamos longe da universalização do ensino médio, como vimos anteriormente, o acesso à educação superior quadruplicou nas últimas décadas. Porém, não houve inflação de diplomas de ensino superior no Brasil, com exceção de algumas áreas das Ciências Sociais Aplicadas, segundo Menezes Filho (2012). Em áreas como tecnologia, engenharias e serviços sociais (educação, saúde etc.) o aumento do número de graduados foi absorvido pelo crescimento econômico e ampliação dos gastos sociais brasileiros na década de 2000 . 
Zanten (2013) apresenta-nos o outro lado da reprodução social por meio da educação, aquela voltada para as elites econômicas e culturais. A autora apresenta, em linhas gerais, como o sistema de educaçáo para as elites se desenvolveu, no último século, em três países hegemônicos no cenário global: França, Reino Unido e Estados Unidos. Nos Estados Unidos, o topo do sistema educacional ainda é composto pelas seletas universidades (na maioria fundações de direito privado) da Ivy League, que tem grande autonomia no recrutamento de seus estudantes, apesar da implantação de algum sistema de ações afirmativas baseado, principalmente, em critérios étnicos ${ }^{8}$. No Reino Unido, as universidades de ponta são Oxford e Cambridge que, a princípio, possuíam bastante autonomia no recrutamento dos seus estudantes, mas, com o aumento da participação estatal no seu financiamento, ao longo do século XX, a seleção tornou-se mais próxima ao do restante do sistema de educação superior britânico. Na França, o topo do sistema escolar é composto das grandes escolas, que formam a elite dos quadros públicos e privados e cujo acesso, há bastante tempo, é formalmente universalista e meritocrático, apesar de já ter sido mostrado pela teoria da reprodução que nelas se formou uma nobreza de estado (BOURDIEU, 1989) praticamente hereditária.

Dubet, Duru-Bellat e Vérétout (2012) demonstram, de forma quantitativa, que a tendência à reprodução escolar pelo sistema de ensino varia fortemente de um país para outro (sua comparação dá-se entre países relativamente comparáveis, todos eles desenvolvidos). Assim, muitas variáveis influenciam no grau da reprodução social pela escola, tais como o nível de desigualdade na sociedade em geral, a influência do sistema escolar na alocação de cargos e posiçóes e a duração do tronco comum de ensino, dentre outras. Por um lado, há países como a França onde, apesar da relativamente pequena desigualdade global na sociedade, ela é fortemente determinada pelo sistema escolar, enquanto em outros países, como nos Estados Unidos, também há forte influência do sistema escolar, apesar de a desigualdade geral na sociedade ser maior. Por outro lado, há países relativamente pouco desiguais onde a alocação de posiçóes sociais passa pouco pelo sistema escolar, como a Dinamarca e, por fim, há também países bastante desiguais cujas desigualdades são pouco determinadas pelo sistema escolar, como a Itália.

Dessa forma, o autor demonstra que a lei boudieusiana da reprodução social pelo sistema escolar varia de acordo com diferentes arranjos societários e institucionais. Apesar da pouca comparabilidade do Brasil com os países escolhidos pelo autor, seria importante entender o quanto de nossas desigualdades econômicas e sociais passam pelo sistema escolar.

Estudos quantitativos sobre educaçáo são relativamente comuns na Sociologia da Educação Brasileira e em áreas correlatas e muitos deles são inspirados nas Teorias da Reprodução. Entre esses estudos, podemos citar o de Valle Silva (2003), que focou nos efeitos dos condicionantes socioeconômicos sobre as transiçóes escolares no ensino básico com o uso de regressóes logísticas; o de Ribeiro 
(2011), interessado em explicar com regressóes lineares os anos de escolarização a partir dos dados da PNAD; o de Ceniviva e Brito (2014), um amplo estudo longitudinal que busca nos dados dos censos entre 1960 e 2010 os fatores que explicam o sucesso nas transiçôes escolares desde a educação básica até o ensino superior; e o de Tavares Júnior, Montalvão e Neubert (2015), também interessado nas transições escolares na educação básica a partir dos dados das PNADs.

Nosso estudo diferencia-se dos anteriores por utilizar o banco de dados do questionário socioeconômico do ENEM como fonte dos dados empíricos. O ENEM, apesar de existir desde 1998 e de ser utilizado para conceder bolsas do ProUni desde 2005, apenas em 2009 passou a ser utilizado de forma ampla para o acesso nas universidades públicas. Se, por um lado, tem as deficiências de um questionário autoaplicado, com grande perda de dados e missings, por outro lado oferece informações extremamente ricas para a Sociologia da Educação, informaçôes bastante pertinentes do ponto de vista sociológico que não estão disponíveis em bases de dados como os censos demográficos e as PNADs, tais como hábitos de leitura, tipo de escola cursada no ensino médio etc.

\section{Resultados}

O Quadro 2 traz estatísticas descritivas relativas à amostra utilizada? .

\section{Quadro 2}

Estatísticas descritivas da amostra*.

\begin{tabular}{|c|c|}
\hline Variável & Tendências \\
\hline Idade & média: 24; mediana: 21 ; moda: 18 ; desvio-padrão; 7,6 anos \\
\hline Sexo & $59,8 \%$ mulheres \\
\hline Cor ou raça & $52,9 \%$ não brancos \\
\hline Região do país & $\begin{array}{c}43,9 \% \text { Sudeste: } 25,2 \% \text { Nordeste; } 14,7 \% \text { Sul; } \\
\text { 8,3\% Centro-oeste; } 7,9 \% \text { Norte }\end{array}$ \\
\hline Tipo de escola & $81,2 \%$ escola pública \\
\hline Religião & $60,1 \%$ católicos, $25,3 \%$ protestantes e evangélicos, $3,1 \%$ espíritas \\
\hline Densidade do lar & $66,2 \%$ quatro pessoas ou menos no domicílio \\
\hline Filhos & $84,4 \%$ não têm filhos \\
\hline Escolaridade dos pais & $17,9 \%$ das mães e $13,7 \%$ dos pais cursaram ensino superior \\
\hline Reprovação & $84,4 \%$ não reprovou no ensino médio \\
\hline Turno & $56,4 \%$ estudaram apenas no turno diurno \\
\hline Trabalho & $62,5 \%$ trabalharam durante o ensino médio \\
\hline Renda & $\begin{array}{c}84,5 \% \text { têm renda familiar de até } 5 \text { salários mínimos. } \\
0,8 \% \text { tem renda superior a } 30 \text { salários mínimos }\end{array}$ \\
\hline
\end{tabular}

${ }^{*} N=82.720$. 
Sobre as características da "demanda qualificada", nota-se, em primeiro lugar, que a idade predominante é compatível com o período de finalização do ensino médio e os anos subsequentes, embora candidatos mais velhos não sejam raros. Mulheres formam a maioria, bem como não-brancos. A participação das regiôes geográficas é relativamente equilibrada, representando a distribuição populacional. Em termos de religião, a maioria dos candidatos se declara cristã $(85,4 \%$ são, ao menos nominalmente, católicos, evangélicos e protestantes históricos). Grande parte vem de domicílios com quatro integrantes ou menos, bem como a imensa maioria não tem filhos. Uma minoria possui pais que cursaram ensino superior, embora seja mais comum que a mãe tenha alcançado esse nível de ensino. Reprovaçóes durante o ensino médio foram relativamente raras entre os candidatos. Pouco mais da metade estudou exclusivamente no turno diurno, enquanto a maioria trabalhou durante os anos de ensino médio. Por fim, predominaram rendas familiares baixas entre os candidatos: a maioria possui renda familiar inferior a cinco salários mínimos.

Optamos por trabalhar com um modelo do tipo "stepwise" (RAMOS, 2014) adicionando, aos poucos, os conjuntos de variáveis representativos de cada dimensão analítica. Os primeiros modelos, apresentados na Tabela 1, são referentes às variáveis representativas de capital econômico. Nota-se, em primeiro lugar, significância estatística ${ }^{10}$ de quase todas as categorias (com exceção da variável sobre trabalho no ensino médio relativo ao modelo para o curso de mMedicina). O impacto da renda (observado a partir do exponencial de beta) é bastante elevado. Estudantes com rendas típicas da classe média (no caso, entre 10 e 30 salários mínimos) possuem, em relação aos candidatos com renda familiar inferior a 2 salários mínimos, chances 4,1 vezes maiores de atingir a nota mínima para ingresso no curso de Pedagogia, 8,3 vezes no curso de Administração e 21,5 vezes (ou seja, mais de $2.000 \%$ ) no curso de Medicina.

\section{Tabela 1}

Modelo 1: capital econômico.

\begin{tabular}{|c|c|c|c|c|c|c|}
\hline & \multicolumn{2}{|c|}{ Pedagogia } & \multicolumn{2}{|c|}{ Administraçáo } & \multicolumn{2}{|c|}{ Medicina } \\
\hline & $\exp B$ & sig & $\exp B$ & sig & $\exp B$ & sig \\
\hline Até 2 salários mínimos (referência) & & 0,000 & & 0,000 & & 0,000 \\
\hline De 2 a 5 salários mínimos & 1,921 & 0,000 & 2,252 & 0,000 & 4,443 & 0,000 \\
\hline De 5 a 10 salários mínimos & 2,728 & 0,000 & 4,428 & 0,000 & 13,477 & 0,000 \\
\hline De 10 a 30 salários mínimos & 4,134 & 0,000 & 8,318 & 0,000 & 21,532 & 0,000 \\
\hline Mais de 30 salários mínimos & 3,096 & 0,000 & 7,699 & 0,000 & 19,777 & 0,000 \\
\hline Trabalhou durante o ensino médio & 0,917 & 0,002 & 0,868 & 0,020 & 0,746 & 0,108 \\
\hline Mais de 5 pessoas no domicílio & 0,800 & 0,000 & 0,679 & 0,000 & 0,647 & 0,035 \\
\hline Constante & 0,372 & 0,000 & 0,033 & 0,000 & 0,002 & 0,000 \\
\hline $\mathrm{N}$ & \multicolumn{2}{|c|}{25.828} & \multicolumn{2}{|c|}{25.835} & \multicolumn{2}{|c|}{25.836} \\
\hline R2 Negelkerke & \multicolumn{2}{|c|}{0,05} & \multicolumn{2}{|c|}{0,059} & \multicolumn{2}{|c|}{0,086} \\
\hline
\end{tabular}

Exp B: exponencial de beta, ou razöes da chance; Sig: significância; n: amostra; $R^{2}$ : coeficiente de determinação. Fonte: com base nos dados obtidos em ENEM, 2009. 
Quando a renda ultrapassa os 30 salários mínimos, porém, há relativa queda nas chances (embora permaneçam elevadas em comparação com a dos candidatos de baixa renda) em relação à renda familiar típica da classe média alta. As classes altas, fortemente dotadas de capital econômico, possuem outros espaços de reproduçáo social que náo o sistema de ensino, como a herança e o casamento, por exemplo. Para as classes médias - pelo menos naquelas fraçóes que dependem mais fortemente da incorporação de algum tipo de capital cultural - a relação com diplomas é fundamental para garantir sua reprodução social enquanto classe, seja nas profissóes liberais, seja no acesso a empregos públicos no Estado.

O fato de ter trabalhado no ensino médio diminui as chances de atingir a nota mínima em 8,3\% no modelo relacionado ao curso de Pedagogia e em 13,2\% no curso de Administração, mesmo levando em conta a renda familiar. A diminuição do tempo disponível para o estudo se manifesta em um rendimento menor no ENEM. Por sua vez, utilizou-se a variável sobre a densidade no domicílio como um proxy da condição econômica da família e, também, tendo em vista a hipótese de que famílias menores podem investir mais, individualmente, em seus estudantes. Como era de se esperar, as diminuiçóes das chances para candidatos oriundos de famílias maiores variam de $20 \%$ no caso do curso de Pedagogia a 35,3\% no caso do curso de Medicina.

Apesar da significância alta de muitas variáveis independentes, o poder explicativo dos modelos sobre as chances de ingresso foi relativamente baixo variando de 5\% no modelo relativo ao curso de Pedagogia a $8,6 \%$ no caso do modelo relativo ao curso de Medicina.

$\mathrm{Na}$ Tabela 2 temos as mesmas variáveis independentes apresentadas na Tabela 1, com a adição das variáveis demográficas. Houve uma pequena diminuição do impacto da renda familiar. Por exemplo, em relação às rendas entre 10 e 30 salários mínimos, o impacto passou de 4,1 para 3,8 no modelo relativo ao curso de Pedagogia e de 8,3 para 6,6 no curso de Administração. Não obstante, houve aumento do impacto das rendas maiores de 30 salários mínimos no caso dos modelos relativos aos cursos de Administração e Medicina. As variáveis relativas ao trabalho no ensino médio e à densidade do domicílio perderam significância estatística.

Muitas das variáveis demográficas tiveram impacto significativo sobre as chances de um candidato atingir a nota mínima, considerando os prováveis efeitos $\mathrm{da}$ autosseleção sobre os quais tratamos. $\mathrm{O}$ impacto da idade foi significativo em todos os modelos. Cada ano a mais de idade está relacionado com uma diminuição nas chances de 4,1\% no caso do curso de Pedagogia, 7,2\% no caso do curso de Administração e de incríveis 33,3\% no caso do modelo relativo ao curso de $\mathrm{Me}$ dicina. Provavelmente, a distância temporal em relação aos conteúdos da prova, vinculados ao ensino médio, possa explicar essa diminuição, bem como o atraso 
escolar correlacionado com a maior idade. $\mathrm{O}$ gênero foi significativo no modelo do curso de Pedagogia, com mulheres atingindo uma chance 44,2\% maior em relação aos homens. Embora os resultados não sejam significativos, resultados semelhantes foram encontrados nos outros dois modelos. Segundo Bourdieu (2014), as meninas saem-se melhor em todos os níveis do sistema escolar porque são socializadas para serem mais dóceis, aceitando mais passivamente, em relação aos meninos, a autoridade pedagógica da escola. Adicionalmente, a entrada preco-

\section{Tabela 2}

Modelo 2: Capital econômico e variáveis demográficas.

\begin{tabular}{l|c|c|c|c|c|c}
\hline \multirow{2}{*}{} & \multicolumn{5}{c}{ Curso } \\
\cline { 2 - 7 } & \multicolumn{2}{|c|}{ Pedagogia } & \multicolumn{2}{c}{ Administraçáo } & \multicolumn{2}{c}{ Medicina } \\
\cline { 2 - 7 } & exp B & sig & exp B & sig & exp B & sig \\
\hline Até 2 salários mínimos (referência) & & 0,000 & & 0,000 & & 0,000 \\
\hline De 2 a 5 salários mínimos & 1,807 & 0,000 & 2,174 & 0,000 & 5,447 & 0,004 \\
\hline De 5 a 10 salários mínimos & 2,331 & 0,000 & 3,271 & 0,000 & 7,022 & 0,005 \\
\hline De 10 a 30 salários mínimos & 3,880 & 0,000 & 6,633 & 0,000 & 21,121 & 0,000 \\
\hline Mais de 30 salários mínimos & 2,486 & 0,003 & 8,193 & 0,000 & 22,213 & 0,007 \\
\hline Trabalhou durante o EM & 0,963 & 0,503 & 0,865 & 0,260 & 1,045 & 0,911 \\
\hline Mais de 5 pessoas no domić́lio & 0,962 & 0,478 & 0,866 & 0,268 & 1,908 & 0,080 \\
\hline Idade & 0,959 & 0,000 & 0,928 & 0,010 & 0,667 & 0,043 \\
\hline Sexo feminino & 1,442 & 0,000 & 1,218 & 0,114 & 1,696 & 0,171 \\
\hline Branco & 1,213 & 0,000 & 1,332 & 0,032 & 1,648 & 0,230 \\
\hline Sudeste (referência) & & 0,000 & & 0,594 & & 0,398 \\
\hline Sul & 0,758 & 0,000 & 1,003 & 0,985 & 0,455 & 0,163 \\
\hline Centro-oeste & 0,653 & 0,000 & 0,714 & 0,181 & 0,298 & 0,243 \\
\hline Nordeste & 0,696 & 0,000 & 1,122 & 0,503 & 1,329 & 0,573 \\
\hline Norte & 0,669 & 0,000 & 0,921 & 0,765 & 1,320 & 0,717 \\
\hline Católica (referência) & & 0,000 & & 0,000 & & 0,182 \\
\hline Protestante ou evangélica & 1,126 & 0,053 & 1,373 & 0,031 & 0,839 & 0,734 \\
\hline Espírita & 1,811 & 0,000 & 1,996 & 0,026 & 2,757 & 0,186 \\
\hline Outra religião & 1,410 & 0,000 & 2,122 & 0,000 & 2,298 & 0,087 \\
\hline Tem filhos & 0,747 & 0,016 & 0,540 & 0,077 & 0,000 & 0,988 \\
\hline Constant & 0,482 & 0,000 & 0,064 & 0,000 & 0,751 & 0,939 \\
\hline N & 8.502 & & 8.508 & & 8.508 \\
\hline & 0,094 & & 0,085 & & 0,15 \\
\hline & & & & & \\
\hline
\end{tabular}

Exp B: exponencial de beta, ou razóes da chance; Sig: significância; $n$ : amostra; $R^{2}$ : coeficiente de determinação. Fonte: com base nos dados obtidos em ENEM, 2009. 
ce dos homens no mercado de trabalho pode impactar a escolarização masculina. Em 2010, mais de 75\% dos homens com 20 anos estavam no mercado de trabalho, contra menos de 60\% das mulheres (GUIMARÁES; BARONE; BRITO, 2015). Estudantes declarados brancos tiveram chances maiores em relação aos não-brancos: as chances são $21 \%$ maiores no curso de Pedagogia, $33 \%$ no curso de Administração e quase $65 \%$ no curso de Medicina, embora não seja significativo nesse último caso (em virtude, provavelmente, do baixo número de casos que atingem a nota necessária para ingresso nesse curso), o que reflete as condições socioeconômicas de relativa desvantagem de negros e pardos.

Por sua vez, a regiáo do país onde estudou o candidato é significativa no caso do curso de Pedagogia. Em relação a candidatos que estudaram no Sudeste, candidatos do Sul tem 24,2\% menos chances, candidatos do Centro-oeste $34,7 \%$ menos, enquanto candidatos do Norte e Nordeste possuem chances 33,1 e 30,4\% menores, respectivamente. Como o Sudeste é o centro econômico e cultural do país, há uma hierarquização geográfica das chances de sucesso com essa região na dianteira, seguida - muito distante — pelo Sul e pelo Nordeste. Com as menores chances estão os candidatos das regióes menos urbanizadas e povoadas do país, o Centro-oeste e o Norte. A religiáo, por sua vez, é uma variável problemática, pois agrupa na mesma categoria (por exemplo, protestantes) condiçóes sociais extremamente diversas: pentecostais e neopentecostais, predominantes nas classes baixas das periferias das grandes cidades, e protestantes históricos, predominantes, sobretudo, em zonas rurais do Centro-sul, com grande proporção de descendentes de imigrantes europeus, como os teuto-brasileiros luteranos. De qualquer forma, em relação aos católicos, protestantes e evangélicos possuem chance $37 \%$ maior de atingir a nota mínima para o curso de Administraçấo. Candidatos espíritas, por sua vez, apresentam aumentos das suas chances de sucesso em mais de $81 \%$ no caso do modelo relativo ao curso de Pedagogia e de quase $100 \%$ no modelo relativo ao curso de Administração. É possível que haja relação com o fato de ser uma religião típica das classes médias urbanas, com maior escolaridade e com alta valorização da palavra escrita e da literatura em suas práticas litúrgicas ${ }^{11}$.

Por fim, ter filhos diminui as chances em mais de $25 \%$ no caso do modelo do curso de Pedagogia e em 46\% no curso de Administração (o efeito não é estatisticamente significativo ao nível padrão de 5\%, mas é ao nível de 10\%). O impacto do cuidado dos filhos, sobretudo sobre as mulheres, pode diminuir substancialmente o tempo disponível para o estudo. O poder explicativo, medido pelo R2 dos modelos, foi maior do que os do modelo 1 - chegou a $15 \%$ no caso do modelo relativo ao curso de Medicina.

Os modelos 3, apresentado na Tabela 3, por sua vez, incorporam, além das variáveis operacionalizadoras do capital econômico e das variáveis demográficas, aquelas relativas ao capital cultural do candidato e de sua família, seja a partir de sua di- 
Tabela 3

Modelo 3: Capital econômico, variáveis demográficas e capital cultural.

\begin{tabular}{|c|c|c|c|c|c|c|}
\hline & \multicolumn{6}{|c|}{ Curso } \\
\hline & \multicolumn{2}{|c|}{ Pedagogia } & \multicolumn{2}{|c|}{ Administração } & \multicolumn{2}{|c|}{ Medicina } \\
\hline & $\exp B$ & sig & $\exp B$ & sig & $\exp B$ & sig \\
\hline Até 2 salários mínimos (referência) & & 0,000 & & 0,000 & & 0,093 \\
\hline De 2 a 5 salários mínimos & 1,505 & 0,000 & 1,772 & 0,001 & 3,469 & 0,038 \\
\hline De 5 a 10 salários mínimos & 1,454 & 0,000 & 1,795 & 0,012 & 1,883 & 0,429 \\
\hline De 10 a 30 salários mínimos & 2,012 & 0,000 & 3,020 & 0,000 & 6,534 & 0,015 \\
\hline Mais de 30 salários mínimos & 1,490 & 0,278 & 3,739 & 0,010 & 6,070 & 0,157 \\
\hline Trabalhou durante o ensino médio & 1,143 & 0,036 & 1,006 & 0,967 & 1,316 & 0,513 \\
\hline Mais de 5 pessoas no domicílio & 1,056 & 0,358 & 0,951 & 0,724 & 2,506 & 0,019 \\
\hline Idade & 0,969 & 0,000 & 0,960 & 0,130 & 0,672 & 0,115 \\
\hline Sexo feminino & 1,800 & 0,000 & 1,619 & 0,001 & 2,384 & 0,032 \\
\hline Branco & 1,086 & 0,179 & 1,062 & 0,686 & 1,202 & 0,680 \\
\hline Sudeste (referência) & & 0,000 & & 0,738 & & 0,546 \\
\hline Sul & 0,771 & 0,001 & 1,026 & 0,887 & 0,494 & 0,226 \\
\hline Centro-oeste & 0,613 & 0,000 & 0,737 & 0,254 & 0,306 & 0,264 \\
\hline Nordeste & 0,680 & 0,000 & 1,083 & 0,662 & 1,042 & 0,937 \\
\hline Norte & 0,666 & 0,001 & 0,888 & 0,693 & 1,487 & 0,624 \\
\hline Católica (referência) & & 0,010 & & 0,012 & & 0,692 \\
\hline Protestante ou evangélica & 1,165 & 0,022 & 1,516 & 0,009 & 1,124 & 0,827 \\
\hline Espírita & 1,495 & 0,024 & 1,432 & 0,287 & 1,841 & 0,450 \\
\hline Outra religião & 1,208 & 0,048 & 1,647 & 0,010 & 1,703 & 0,295 \\
\hline Tem filhos & 0,829 & 0,181 & 0,831 & 0,653 & 0,000 & 0,990 \\
\hline Pai tem ensino superior & 1,018 & 0,855 & 1,329 & 0,118 & 1,774 & 0,222 \\
\hline Mãe tem ensino superior & 1,347 & 0,000 & 1,217 & 0,244 & 0,928 & 0,870 \\
\hline Estudou em escola particular & 1,993 & 0,000 & 1,815 & 0,000 & 1,994 & 0,151 \\
\hline Reprovou no ensino médio & 0,971 & 0,724 & 0,963 & 0,861 & 1,712 & 0,439 \\
\hline Estudou no turno noturno & 0,699 & 0,000 & 0,542 & 0,000 & 0,431 & 0,109 \\
\hline Fator de leitura 1 & 0,647 & 0,000 & 0,551 & 0,000 & 0,365 & 0,000 \\
\hline Fator de leitura 2 & 1,351 & 0,000 & 1,651 & 0,000 & 1,735 & 0,004 \\
\hline constant & 0,393 & 0,000 & 0,030 & 0,000 & 0,465 & 0,870 \\
\hline $\mathrm{N}^{*}$ & \multicolumn{2}{|c|}{7.588} & \multicolumn{2}{|c|}{7.594} & \multicolumn{2}{|c|}{7.594} \\
\hline R2 Negelkerke & \multicolumn{2}{|c|}{0,181} & \multicolumn{2}{|c|}{0,184} & \multicolumn{2}{|c|}{0,265} \\
\hline
\end{tabular}

*Quanto mais completo o modelo logístico, maior é a perda do número de casos por causa dos valores faltantes (missing) o que, certamente, aumenta o viés de seleçäo.

Exp B: exponencial de beta, ou razöes da chance; Sig: significância; n: amostra;

$R^{2}$ : coeficiente de determinação. Fonte: com base nos dados obtidos em ENEM, 2009. 
mensão incorporada (por exemplo, por meio de hábitos de leitura), seja mediante a sua dimensão institucionalizada (representada pelas variáveis relativas ao sistema escolar).

A renda familiar permanece significativa e, ainda, é a variável com maior impacto (considerando a razão das chances), apesar de uma diminuição drástica em relação ao primeiro modelo. Rendas entre 10 e 30 salários mínimos aumentam as chances dos candidatos em relação a rendas familiares de até dois salários mínimos, em 101\% no caso do curso de Pedagogia, 202\% no caso do curso de Administração e $553 \%$ no caso do curso de Medicina. É muito, mas menos do que os valores que ultrapassavam a $2.000 \%$ nos dois primeiros modelos. Grande parte de seu impacto foi diluído nas variáveis relacionadas ao capital cultural. Idade e sexo permanecem significativos, embora a cor ou raça não. Estranhamente, uma densidade familiar alta passa a estar associada com uma maior chance no modelo de Medicina, embora os resultados devem ser tomados com cautela, visto que é o grupo que atinge a nota mínima para esse curso forma apenas $1 \%$ da amostra. Por sua vez, a região geográfica permanece significativa no caso do modelo do curso de Pedagogia e a religião neste e no de Administração. Ter filhos, nesses últimos modelos, perde sua significância estatística.

Analisando as variáveis relacionadas ao capital cultural, a escolaridade da mãe é significativa no caso do curso de Pedagogia, com o aumento de $34,7 \%$ das chances em relação aos candidatos cujas mães não cursaram o ensino superior. Essa influência, provavelmente, dá-se pelo papel que a genitora costuma ter, em relação ao pai, na escolarização dos filhos (CARVALHO, 2000). Quando passamos para as variáveis relacionadas à trajetória escolar, observamos que um histórico de repetência não tem impacto significativo sobre as chances de atingir a nota mínima em nenhum dos três cursos (o que pode derivar da correlação entre repetência e idade, variável já analisada anteriormente). Por outro lado, ter estudado em escolas particulares, em geral de melhor qualidade, praticamente dobra as chances dos candidatos no modelo relativo ao curso de Pedagogia e aumenta em mais de $80 \%$ no caso do modelo relativo ao curso de Administração em relação aos estudantes provenientes das escolas públicas - lembramos que, por se tratar de um modelo multivariado, esse resultado já leva em conta outras variáveis como a renda familiar ou a escolaridade dos pais.

O turno de frequência à escola também impacta nas chances de sucesso. Mesmo levando em conta o tipo de escola e se o estudante trabalhava, candidatos do turno noturno possuem chances significativamente menores em relação àqueles que estudaram durante o dia. As chances diminuem em 40\% no modelo relativo ao curso de Pedagogia, em 55\% no modelo relativo ao curso de Administração e em mais de $56 \%$ no modelo relativo ao curso de Medicina (embora náo significativo nesse último caso). É provável que o ensino, de uma forma geral, seja mais fraco, ao menos em relação à preparação para o tipo de exame que é o ENEM, nesse turno, que atende uma demanda de estudantes, em grande parte, trabalhadores. 
Resultados bastante interessantes estão relacionados aos hábitos de leitura dos candidatos. Para facilitar a análise em um modelo de regressão, agrupamos os hábitos de leitura em dois fatores, a partir de uma análise de componentes principais $^{12}$, conforme já detalhamos. Há uma clara diferença entre os hábitos considerados culturalmente legítimos, agrupados no fator 2, e os hábitos considerados culturalmente pouco legítimos, com menor prestígio social, agrupados no fator $1^{13}$. Enquanto aqueles produzem aumentos das chances, mesmo considerando outras variáveis constantes, esses produzem decréscimo nas chances. Assim, temos como hábitos "culturalmente legítimos aqueles relacionados com aumentos nas chances de sucesso: jornais, revistas de informação geral, revistas de divulgação científica, de educação, livros de ficção (poesia, literatura etc.) e de não ficção (biografias, livros jornalísticos etc.) e enciclopédias ou dicionários. Entre os hábitos pouco legítimos e relacionados com decréscimo nas chances de sucesso escolar temos revistas de humor, para adolescentes, sobre comportamento, esportes, saúde e religião.

Para cada unidade de aumento na pontuação no fator 1 (o que agrupa as leituras culturalmente menos legítimas), as chances diminuem em 35\% no modelo relativo ao curso de Pedagogia, 45\% no modelo do curso de Administração e $63 \%$ no modelo relativo ao curso de Medicina. Por sua vez, cada unidade de aumento na pontuação do fator 2 (que reúne as leituras mais legítimas) está associada com um aumento de 35\% nas chances relativas dos candidatos no modelo do curso de Pedagogia, 65\% no modelo do curso de Administração e 73\% no de Medicina. Os coeficientes estão correlacionados com a maior ou menor dificuldade em atingir a nota relativa a cada curso. Na Figura 1, temos um scatterplot relacionando a nota e ambos os fatores. Note-se a tendência ascendente no segundo caso

\section{Figura 1}

Relação entre fatores de leitura e nota final da prova.

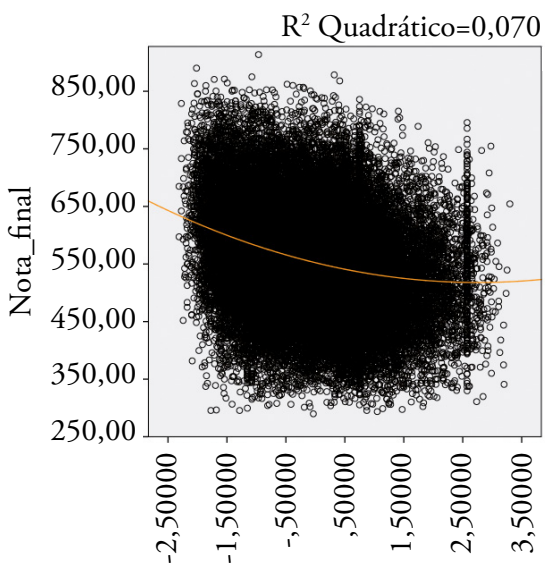

Fator 1 - Leitura

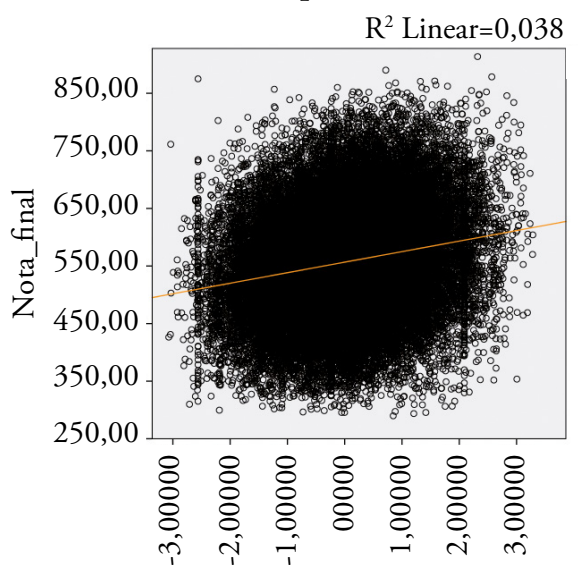

Fator 2 - Leitura

Fonte: com base nos dados obtidos em ENEM, 2009. 
e descendente no primeiro caso. Por fim, com a inclusão das variáveis relacionadas ao capital cultural, o poder explicativo dos modelos aumenta bastante. As variáveis incluídas preveem 18,1\% do sucesso no curso de Pedagogia, $18,5 \%$ do sucesso no curso de Administração e 26,5\% do sucesso no modelo do curso de Medicina. Sáo valores relativamente altos para modelos logísticos cujas unidades de análise são indivíduos e cujas variáveis dependentes e independentes são atributos sociais.

\section{Considerações finais}

Nessa tentativa de ordenar a realidade a partir de modelos estatísticos representativos de uma massa enorme de dados que representam milhóes de casos de abrangência nacional conseguimos, de certa forma, resultados que, se por um lado subsidiam a teoria da reprodução em um contexto nacional, por outro também levam a algumas generalizaçóes empíricas interessantes sobre as particularidades da situação brasileira. Em primeiro lugar, muitos resultados foram, dentro de certa margem, uma verificação empírica de prediçôes teóricas. $\mathrm{O}$ capital cultural é importante, tanto o herdado quanto o adquirido, bem como o institucionalizado. $\mathrm{O}$ ambiente familiar, representado por indicadores de capital econômico — a renda — , bem como de capital cultural (escolaridade dos pais) tem um papel-chave sobre as chances de sucesso dos concorrentes. Ainda assim, não é possível negligenciar o efeito da escola, independente dos efeitos do ambiente familiar.

Por outro lado, disposiçóes culturalmente legítimas, como aquelas relacionadas a certos hábitos de leitura, cumprem igual papel. A desigualdade que se observa no sistema escolar como um todo desde o início tem, na passagem do ensino médio para o superior, o seu ponto fulcral. Nesse momento, o passado incorporado - mas também institucionalizado, indicado pelo tipo de escola frequentado, turno, modalidade etc. - pode ser tanto um fardo, para uns, quanto um propulsor, para outros, nessa batalha desigual por recursos socialmente escassos.

Uma pesquisa, porém, sempre tem seus imprevistos e dados instigantes surgem para desestabilizar o estado atual de conhecimento e ajudar a levá-lo mais longe. A influência muito forte do capital econômico (indicada pelo aumento das razóes das chances dos candidatos de alta renda) que, com o efeito já controlado pelas outras variáveis, chega a elevar em mais de $500 \%$ as chances de um concorrente atingir uma vaga no curso de Medicina, bastante superior à influência de qualquer indicador de capital cultural, sugere que aquele ainda é um capital bastante influente no campo escolar - não que em outros contextos ele deixe de sê-lo de alguma forma influente - às vezes mais do que o próprio capital cultural, o capital por excelência desse campo. O campo escolar brasileiro pode não ser, ainda, suficientemente autonomizado como em sociedades plenamente modernizadas, onde a autonomia entre os campos é maior. 


\section{Notas}

1. A taxa líquida de acesso ao ensino superior é calculada pelo percentual da população entre 18 e 24 anos com acesso ao ensino superior. A taxa bruta, por sua vez, calcula o total de estudantes com acesso ao ensino superior, independentemente da idade, sobre a população entre $18 \mathrm{e}$ 24 anos. Por essa razão, essa taxa pode ultrapassar $100 \%$.

2. Entre elas, podemos citar o Programa Universidade para Todos (ProUni), o Fundo de Financiamento Estudantil (Fies), as políticas de reserva de vagas (cotas étnicas, sociais e outras) etc.

3. Como exemplos de definição de sucesso escolar para fins heurísticos, Lahire (1997) define-o como ter atingido a nota 6 na avaliação nacional francesa da $3^{\text {a }}$ série do ensino fundamental. Piotto (2008) e Vianna (2005) também entendem, assim como nós, o sucesso escolar como a permanência dos estudantes até o ensino superior, o que também denominam de longevidade escolar. Pereira (2005), para fins de sua pesquisa, entende o sucesso escolar como o acesso a uma competitiva escola secundária mineira, com rígido e concorrido processo seletivo.

4. A escolha por esses cursos se deu devido ao fato de serem cursos com grande número de matrículas (Administração com mais de 800 mil, Pedagogia com mais de 600 mil e Medicina com mais de 100 mil) e cada um deles representante de uma categoria de prestígio social, considerando apenas a concorrência e a correspondente nota mínima necessária para ingresso: baixo prestígio (Pedagogia), médio prestígio (Administração) e alto prestígio (Medicina).

5. A técnica da regressão logística permite explicar uma variável dependente dicotômica a partir de variáveis independentes numéricas ou categóricas. Assim, podemos indicar, por exemplo, quais as chances de um estudante cuja mãe tenha cursado o ensino superior tem de atingir a nota mínima para o curso de medicina em relação aos estudantes cuja mãe não tenha ensino superior.

6. Por causa das dificuldades de processamento enfrentadas ao se trabalhar com bancos de dados muito grandes, foi retirada uma amostra aleatória de $2 \%$ do total de casos, totalizando uma amostra de 82.720 respondentes, o que resulta em uma margem de erro inferior a $1 \% \mathrm{em}$ um nível de confiança de $95 \%$.

7. Há uma relação interessante entre esse tipo de capital e o capital econômico, pois é necessário algum capital econômico para adquiri-los, porém, para se aproximar de forma simbólica desses bens é necessário possuir os códigos necessários para sua interpretação, ou seja, possuir capital cultural incorporado.

8. A seleção para as altas escolas americanas continua sendo bastante vinculada ao capital econômico e ao capital social: largam na frente estudantes filhos de pais que estudaram nessas universidades e que contribuíram financeiramente com doações, o que é bastante comum nos Estados Unidos. Segundo a autora, nos poucos momentos em que houve algum critério de seleção estritamente meritocrático e universalista, ele foi logo abandonado devido ao sucesso desproporcional de jovens estudantes judeus brilhantes, oriundos principalmente das novas classes médias e altas americanas. 
9. Para fins de operacionalidade no software SPSS, extraiu-se uma amostra aleatória do banco de dados disponibilizado pelo Instituto Nacional de Estudos e Pesquisas Educacionais Anísio Teixeira (INEP, 2009). Lembramos que foram incluídos no modelo apenas os casos de candidatos que não zeraram alguma das provas.

10. Consideramos significativos do ponto de vista estatístico valores inferiores a $\mathrm{p}<0,05$.

11. A esse respeito, ver Lewgoy (2000).

12. Técnica que visa reduzir um grande número de variáveis numéricas ou ordinais a um conjunto significativamente menor de variáveis. No caso do presente artigo, encontramos duas variáveis, ou fatores.

13. No Anexo 1, detalhamos a composição dos fatores extraídos com a técnica de Análise de Componentes Principais.

\section{Referências}

BOURDIEU, P. A Distinção: crítica social do julgamento. São Paulo: Edusp, 2007.

BOURDIEU, P. A Dominaçáo Masculina: a condição feminina e a violência simbólica. Rio de Janeiro: BestBolso, 2014.

BOURDIEU, P. La noblesse d'État: Grands corps et grandes écoles. Paris: Editions de Minuit, 1989.

BOURDIEU, P.; PASSERON, J.-C. A reproduçáo: elementos para uma teoria do sistema de ensino. 2. ed. Rio de Janeiro: Francisco Alves, 1982.

BOURDIEU, P.; PASSERON, J.-C. Los Herederos: los estudiantes e la cultura. Buenos Aires: Sigloveinteuno, 2008.

BRASIL. Pesquisa nacional por amostra de domicílios. Rio de Janeiro: Instituto Brasileiro de Geografia e Estatística, 1992-2005.

CARVALHO, M. E. P. de. Relaçóes entre família e escola e suas implicaçóes de gênero. Cadernos de Pesquisa, n. 110, p. 143-155, 2000. http://dx.doi.org/10.1590/ $\underline{\text { S0100-15742000000200006 }}$

CENEVIVA, R.; BRITO, M. M. A. de. Estratificação Educacional entre Jovens no Brasil 1960 a 2010. In: RIBEIRO, C. A. C. (org.). Juventudes e Educaçáo. Rio de Janeiro: Azougue, 2014. p. 81-114.

DEROUET, J.-L. A sociologia das desigualdades em educaçáo posta à prova pela segunda explosão escolar: deslocamento dos questionamentos e reinício da crítica. Revista Brasileira de Educaçáo, p. 5-16, 2002. http://dx.doi.org/10.1590/S1413-24782002000300002

DUBET, F; DURU-BELLAT, M.; VÉRÉTOUT, A. As desigualdades escolares antes e depois da escola: organização escolar e influência dos diplomas. Sociologias, v. 14, p. 22 70, 2012. http://dx.doi.org/10.1590/S1517-45222012000100003 
GUADILLA, C. G. Financiamiento de la educación superior en América Latina. Sociologias, Porto Alegre, n. 17, jun. 2007.

GUIMARÃES, N. A.; BARONE, L. S.; BRITO, M. M. A. de. Mercado e mercantilização do trabalho no Brasil (1960-2010). In: ARRETCHE, M. (org.). Trajetórias das desigualdades: como o Brasil mudou nos últimos cinquenta anos. São Paulo: Editora Unesp, 2015.

INSTITUTO BRASILEIRO DE GEOGRAFIA E ESTATÍSTICA (IBGE). Censo Demográfico de 2010. Rio de Janeiro: IBGE, 2010.

INSTITUTO NACIONAL DE ESTUDOS E PESQUISAS EDUCACIONAIS ANÍSIO TEIXEIRA (INEP). Dados do Questionário Socioeconômico do ENEM 2009. Brasil: INEP, 2009. Disponível em: <http://portal.inep.gov.br/web/guest/dados $>$. Acesso em: 2 jun. 2018.

INSTITUTO NACIONAL DE ESTUDOS E PESQUISAS EDUCACIONAIS ANÍSIO TEIXEIRA (INEP). Microdados do Exame Nacional do Ensino Médio de 2009. Disponível em: <http://portal.inep.gov.br/microdados>. Acesso em: 12 set. 2018.

LAHIRE, B. Sucesso escolar nos meios populares: as razóes do improvável. São Paulo: Ática, 1997.

LEWGOY, B. Os espíritas e as letras: um estudo antropológico sobre cultura escrita e oralidade no espiritismo kardecista. Tese (Doutorado) - Universidade Federal do Rio Grande do Sul, Porto Alegre, 2000.

MENEZES FILHO, N. Apagão de Mão de Obra Qualificada? As Profissões e o Mercado de Trabalho Brasileiro entre 2000 e 2010. INSPER - Instituto de Ensino e Pesquisa, 2012. Disponível em: <http://www.insper.edu.br/wp-content/uploads/2012/10/ Apag\%C3\%A3o-de-M\%C3\%A3o-de-Obra-Qualificada-Naercio-Menezes-Filho.docx. pdf>. Acesso em: 2 dez. 2016.

ORGANIZAÇÃO DAS NAÇÓES UNIDAS PARA A EDUCAÇÃO, A CIÊNCIA E A CULTURA (UNESCO). Unesco Institute for Statistics Database. Disponível em: <http://data.uis.unesco.org/Index.aspx>. Acesso em: 10 jun. 2018.

ORGANIZAÇÃO PARA A COOPERAÇÃO E DESENVOLVIMENTO ECONOMMICO (OECD). Education at a Glance 2017: OECD Indicators. Organisation for Economic Cooperation and Development, 2017.

PEREIRA, A. Sucesso escolar de alunos dos meios populares: mobilizaçáo pessoal e estratégias familiares. Dissertação (Mestrado) - Pontifícia Universidade Católica de Minas Gerais, Belo Horizonte, 2005.

PIOTTO, D. C. Trajetórias escolares prolongadas nas camadas populares. Cadernos de Pesquisa,v.38,p.701-707,2008.http://dx.doi.org/10.1590/S0100-15742008000300008

RAMOS, M. P. Pesquisa social: abordagem quantitativa com uso do SPSS. Porto Alegre: Escritos, 2014.

RIBEIRO, C. A .C. Desigualdade de oportunidades e resultados educacionais no Brasil. Dados, v. 54. n. 1, 2011. http://dx.doi.org/10.1590/S0011-52582011000100002 
TAVARES JÚNIOR., F.; MONTALVÃO, A.; NEUBERT, L. F. Rendimento escolar e seus determinantes sociais no Brasil. Revista Brasileira de Sociologia, v. 3, p. 117-137, 2015. http://dx.doi.org/10.20336/rbs. 123

VALLE SILVA, N. do. Expansão escolar e estratificação educacional no Brasil. In: HASENBALG, C.; VALLE SILVA, N. do (orgs.). Origens e destinos. Rio de Janeiro: Topbooks, 2003.

VIANA, M. J. B. As práticas socializadoras familiares como locus de constituição de disposições facilitadoras de longevidade escolar em meios populares. Educaçáo \& Sociedade, Campinas , v. 26, n. 90, p. 107-125, abr. 2005

ZANTEN, A. V. A Sociologia da Educação de Elites. In: APPLE, M. W.; BALL, S.; GANDIN, L. A. (org.). Sociologia da Educaçáa: Análise Internacional. Porto Alegre: Penso, 2013.

Recebido em 27 de novembro de 2017.

Aceito em 04 de setembro de 2018. 
Anexo 1

Matriz de correlação de componentes principais com rotação varimax*.

\begin{tabular}{|c|c|c|}
\hline \multirow{2}{*}{ Frequência de Leitura (nunca $=0$, às vezes $=1$, frequentemente $=2$ ) } & \multicolumn{2}{|c|}{ Fator } \\
\hline & 1 & 2 \\
\hline Jornais & 0,492 & 0,089 \\
\hline $\begin{array}{l}\text { Revistas de informação geral (Carta Capital, Veja, } \\
\text { Istoé, Época, Exame, Caros Amigos, Piaui, Fórum etc.) }\end{array}$ & 0,565 & 0,197 \\
\hline $\begin{array}{l}\text { Revistas de divulgaçáo científica, tecnológica, filosófica ou artística } \\
\text { (Ciência, Galileu, Hoje, Geo, Mente \& Cérebro, Linux Magazine, PC } \\
\text { Magazine, Filosofia, Cult, Nossa História, História Viva, Entrelivros etc.). }\end{array}$ & 0,656 & 0,162 \\
\hline $\begin{array}{l}\text { Revistas de humor, quadrinhos ou jogos } \\
\text { (Casseta \& Planeta, Turma da Mónica, PC Gamer etc.). }\end{array}$ & 0,095 & 0,598 \\
\hline $\begin{array}{l}\text { Revistas para adolescentes ou sobre TV, cinema, música, celebridades } \\
\text { (Viraçäo, TPM, Set, Rolling Stones, Capricho, Contigo, Caras etc.). }\end{array}$ & $-0,013$ & 0,790 \\
\hline $\begin{array}{l}\text { Revistas sobre comportamento, moda, estilo e decoraçáo } \\
\text { (Cláudia, Marie Claire, Pais \& Filhos, Casa \& Jardim, Bons Fluidos etc.). }\end{array}$ & 0,092 & 0,752 \\
\hline $\begin{array}{l}\text { Revistas sobre automóveis, esportes e lazer (Quatro Rodas, Duas Rodas, } \\
\text { Placar, Pesca \& Cia., Náutica, Revista do Vôlei, Viagem, Turismo Terra etc.). }\end{array}$ & 0,252 & 0,358 \\
\hline Revistas sobre saúde (Boa Saúde, Saúde, Vida Simples etc.). & 0,368 & 0,586 \\
\hline $\begin{array}{l}\text { Revistas sobre religiáo (Sophia, Revista das Religiōes, } \\
\text { Missóes, Gospel, Orixás, Delfos etc.). }\end{array}$ & 0,283 & 0,463 \\
\hline $\begin{array}{l}\text { Revistas sobre educação e estudos (Educação, Guia do Estudante, } \\
\text { Almanaque Abril, Sociologia, Lingua Portuguesa, Speak Up etc.). }\end{array}$ & 0,591 & 0,328 \\
\hline Livros de ficção (romances, contos, poesias etc.). & 0,406 & 0,223 \\
\hline $\begin{array}{l}\text { Livros de não-ficção e biografias (reportagens, } \\
\text { livros científicos, filosóficos, históricos, documentários etc.). }\end{array}$ & 0,723 & 0,043 \\
\hline Dicionários, enciclopédias e manuais. & 0,617 & 0,042 \\
\hline
\end{tabular}

${ }^{*} N=42.007$. 